\title{
MODELOVANJE TROFAZNE KAVEZNE ASINHRONE MAŠINE UZ UVAŽAVANJE KONSTRUKCIONIH OSOBENOSTI
}

\section{MODELING OF A THREE-PHASE SQUIRREL CAGE INDUCTION MACHINE CONSIDERING THE CONSTRUCTION FEATURES}

\author{
Ivana Ćirić, Dejan Jerkan, Fakultet tehničkih nauka, Novi Sad
}

\begin{abstract}
Oblast - ELEKTROTEHNIKA I RAČUNARSTVO
Kratak sadržaj - U radu je razvijen dinamički model trofazne kavezne asinhrone mašine sa uvaženim efektima kojima doprinosi specifičnost konstrukcije, kao što je uticaj žljebova na statoru i rotoru razmatrane mašine. $\mathrm{Na}$ modelu koji je razvijen u MATLAB Simulinku su izvršene karakteristične simulacije. Takođe, tako dobijeni rezultati su upoređeni sa rezultatima dobijenim eksperimentalnim putem.
\end{abstract}

Ključne reči: Kavezna asinhrona mašina, metoda konačnih elemenata, MATLAB Simulink, dinamički model, tranzijentni procesi.

\begin{abstract}
In this paper a dynamic model of a threephase squirrel cage induction machine is developed while considering the effects which are contributed by the specificitiy of the construction, such as the influence of the stator's and rotor's grooves of the considered machine. On the model developed in MATLAB Simulink, characteristic simulations were performed. Also, the results thus obtained were compared with the experimental results.
\end{abstract}

Keywords: Squirrel cage induction machine, Finite Element Analysis, MATLAB Simulink, dynamic model, transient processses.

\section{UVOD}

Zahvaljujući maloj masi i zapremini, jednostavnoj konstrukciji, većoj specifičnoj snazi (snaga po jedinici mase) i mogućnostima rada na većim brzinama obrtanja u odnosu na mašine jednosmerne struje, asinhrone mašine predstavljaju najrasprostranjeniju vrstu električnih mašina. Asinhrone mašine su danas široko zastupljene, naročito u savremenoj industriji gde se u pogonima za različite namene koriste kao pogonske mašine.

Ukoliko se govori o primeni asinhronih motora $\mathrm{u}$ industrijskim pogonima, nalaze se u okviru raznih mešalica, mlinova, pumpi, presa, valjaonica, ventilatora, bušilica, ali i raznih drugih uređaja u okviru proizvodnih sistema. U domaćinstvima se primenjuju u različitim vrstama kućnih aparata, kao što su veš mašine, frižideri, klima uređaji, zamrzivači, mikseri, ali i u okviru računara i računarske opreme.

\section{NAPOMENA:}

Ovaj rad proistekao je iz master rada čiji mentor je bio dr Dejan Jerkan, docent.
Poznavanje dinamičkog modela mašina je potrebno za rešavanje problema upravljanja generatorima i motorima, za projektovanje zaštita i nadzora, za određivanje strukture i parametara regulacije u robotici, kao i za rešavanje problema $\mathrm{u}$ automatizaciji proizvodnje, električnim vozilima i drugim sličnim primenama [1]. Osnovni cilj matematičkog modelovanja jeste dobijanje adekvatnog, upotrebljivog i korisnog matematičkog modela koji će zadržati bitne fizičke karakteristike modelovane mašine i suštinski dobro oslikavati prirodu pojava u njoj. Matematičko modelovanje je značajno sa aspekta proučavanja karakteristika, analiziranja različitih radnih režima mašine, kao i razvijanja složenih algoritama za upravljanje istim. Zahvaljujući dovoljno detaljnom matematičkom modelu mašine, pruža se mogućnost računarskih simulacija raznih režima rada i praćenje kako će se u tim, ali i mnogim drugim okolnostima i situacijama modelovana mašina ponašati.

\section{MATEMATIČKI MODEL TROFAZNE KAVEZNE ASINHRONE MAŠINE}

Matematički model koji će biti izložen u nastavku je dinamički jer omogućava proučavanje tranzijentnih pojava u električnim mašinama, dok se ulazni parametri modela dobijaju primenom metode konačnih elemenata. Sam model se oslanja na skup relacija koje su poznate pod imenom višestruko spregnuta električna kola (eng. multiple coupled circuit approach) [2]. Ovakav model, predstavljen $\mathrm{u}$ originalnom, netransformisanom domenu je dovoljno detaljan da prikaže sve pojave od značaja koje su važne za proučavanje trofazne kavezne asinhrone mašine. Kako bi se dobio dovoljno detaljan i upotrebljiv model koji predstavlja matematičku reprezentaciju sistema koji se posmatra, neophodno je uvažiti određene aproksimacije [3]: pojave u električnoj mašini mogu dovoljno detaljno opisati pomoću skoncentrisanih parametara, zanemaruju se pojave kapacitivnog karaktera, nelinearnost feromagnetskog materijala, kao i gubici $u$ magnetskom kolu mašine. Omski otpori statora i rotora su konstantni, kao i momenat inercije rotirajućih masa. Smatra se da nema struja curenja koje se zatvaraju mimo provodnika. Zakošenje štapnih provodnika rotora se izuzima iz razmatranja.

S obzirom na to da rotorski kavez nema električnih pristupa, potrebno je pronaći adekvatan način za definisanje i opisivanje svih pojedinačnih električnih kola kaveza. Najbolje rešenje ovog problema je da se rotorsko kolo predstavi preko rotorskih petlji. Jednu rotorsku petlju 
sačinjava zatvoren provodni put koji se sastoji od dve susedne rotorske šipke i dva naspramna segmenta kratkospojnih prstenova [4].

U nastavku će biti izložene relacije koje opisuju kako električni, tako i mehanički podsistem matematičkog modela trofazne kavezne asinhrone mašine. Diferencijalna jednačina naponske ravnoteže u matričnoj formi može se predstaviti preko sledeće relacije:

$$
\mathbf{u}=\mathbf{R} \cdot \mathbf{i}+\frac{\mathrm{d} \boldsymbol{\Psi}}{\mathrm{dt}}
$$

u - vektor napona svih električnih kola kojima je razmatrana električna mašina modelovana

i - vektor struja statorskih namotaja i svih rotorskih petlji, uključujući i struju kratkospojnog prstena

$\boldsymbol{\psi}$ - vektor svih fluksnih obuhvata statora i rotora

$\mathbf{R}$ - matrica svih statorskih i rotorskih otpornosti

$$
\mathbf{R}=\left[\begin{array}{ll}
\mathbf{R}_{\mathbf{s}} & \\
& \mathbf{R}_{\mathbf{r}}
\end{array}\right]
$$

$\mathbf{R}_{\mathbf{s}}$ - dijagonalna submatrica statorskih otpornosti dimenzija $3 \times 3$

$\mathbf{R}_{\mathbf{r}} \quad$ - submatrica rotorskih otpornosti dimenzija $\left(\mathrm{N}_{\mathrm{B}}+1\right) \mathrm{x}\left(\mathrm{N}_{\mathrm{B}}+1\right)$

Ukoliko se sa $\mathrm{N}_{\mathrm{B}}$ označi broj rotorskih petlji, odnosno broj rotorskih štapnih provodnika, uvažavajući i kratkospojne prstenove, tada postoji $\mathrm{N}_{\mathrm{B}}+1$ nezavisnih strujnih petlji čije struje su posledice postojanja indukovanih elektromotornih sila $u$ njima. Generisanje submatrice statorskih otpornosti $\mathbf{R}_{\mathbf{s}}$ je trivijalno i ona je prosta, dijagonalna matrica otpornosti namotaja statora. Submatrica rotorskih otpornosti $\mathbf{R}_{\mathbf{r}}$ nije dijagonalna matrica jer ona opisuje topologiju rotorskog kaveza, odnosno način uspostavljanja naponske ravnoteže u rotorskim petljama. Uvažavanjem jednačina naponske ravnoteže za sve nezavisne rotorske petlje i uzimajući u obzir ukupnu otpornost tekuće rotorske petlje koja je data kao zbir otpornosi dva kratkospojna prstena i otpornosti dve susedne rotorske šipke, dobija se razvijeni oblik submatrice rotorskih otpornosti.

Naredna matrična jednačina koja predstavlja sastavni deo električnog podsistema matematičkog modela daje vezu između flukseva i struja preko nestacionarne matrice induktivnosti i predstavlja jednačinu za fluksni obuhvat:

$$
\boldsymbol{\psi}=\mathbf{L} \cdot \mathbf{i}
$$

Matrica induktivnosti $\mathbf{L}$ trofazne asinhrone mašine se sastoji od četiri submatrice, te se ona može napisati $u$ sledećem obliku:

$$
\mathbf{L}=\left[\begin{array}{ll}
\mathbf{L}_{\mathrm{ss}} & \mathbf{L}_{\mathrm{sr}} \\
\mathbf{L}_{\mathrm{rs}} & \mathbf{L}_{\mathrm{rr}}
\end{array}\right]
$$

$\mathbf{L}_{\text {ss }}$ - submatrica svih sopstvenih i međusobnih induktivnosti namotaja statora

$\mathbf{L}_{\mathbf{s r}}$ - submatrica statorsko-rotorskih induktivnosti

$\mathbf{L}_{\mathbf{r r}}$ - submatrica svih sopstevnih i međusobnih rotorskih induktivnosti

$\mathbf{L}_{\mathbf{r s}}$ - submatrica rotorsko-statorskih induktivnosti

Submatrica statorskih induktivnosti $\mathbf{L}_{\mathrm{ss}}$ je matrica dimenzija 3x3 na čijoj glavnoj dijagonali se nalaze elementi sopstvenih induktivnosti namotaja statora, dok vandijagonalni elementi predstavljaju koeficijente međusobnih induktivnosti. S obzirom na činjenicu da se $u$ ovom radu uzima u obzir postojanje razlike u magnetskoj permeabilnosti po obodu vazdušnog zazora usled uvažavanja zljebova na statoru i rotoru, elementi matrice
$\mathbf{L}_{\mathbf{s s}}$ nisu nepromenljivi, već su funkcija vremena, odnosno promene relativnog položaja rotora $\mathrm{u}$ odnosu na stator. Submatrica rotorskih induktivnosti $\mathbf{L}_{\mathbf{r r}}$ je znatno složenije forme, te su zbog izuzetno velikog broja međusobnih sprega koje postoje unutar rotorskog kaveza, dimenzije ove matrice $\left(\mathrm{N}_{\mathrm{B}}+1\right) \times\left(\mathrm{N}_{\mathrm{B}}+1\right)$. Pored činjenice da se i u njoj mora uvažiti način opisivanja rotorskog kaveza uvođenjem konturnih struja, uzimanje u obzir promenljivosti ove matrice $\mathrm{u}$ funkciji položaja rotora dodatno komplikuju njenu formu. Submatrice statorskorotorskih $\mathbf{L}_{\mathbf{s r}}$ i rotorsko-statorskih induktivnosti $\mathbf{L}_{\mathbf{r s}}$ su od suštinskog značaja jer se pomoću njih opisuje dominantna komponenta ostvarenog elektromagnetnog momenta. Zbog simetrije submatrica međusobnih induktivnosti, važi da je $\mathbf{L}_{\mathbf{s r}}=\mathbf{L}_{\mathbf{r s}}{ }^{\mathbf{T}}$. Dimenzija submatrice statorsko-rotorskih induktivnosti je $3 \times\left(\mathrm{N}_{\mathrm{B}}+1\right)$. Svi elementi ovih submatrica međusobnih induktivnosti imaju identičan talasni oblik, pri čemu je fazni pomak između elemenata kolona matrice $\mathbf{L}_{\mathrm{sr}}$ jednak $2 \pi / \mathrm{N}_{\mathrm{B}}$, dok su elementi vrsta međusobno fazno pomereni za ugao $2 \pi / 3$. . Pritom, važno je napomenuti da to ne važi za elemente poslednje kolone matrice $\mathbf{L}_{\text {sr }}$ koji opisuju spregu između statorskih namotaja i petlje kratkospojnog prstena, koja je od zanemarivog značaja.

Kako bi matematički model bio potpun, neophodno je prethodno definisanim jednačinama električnog podsistema pridružiti i relacije koje opisuju mehanički podsistem. Izraz za elektromagnetni momenat, odnosno momenat konverzije, dat je sledećom relacijom:

$$
\mathrm{M}_{\mathrm{em}}=\frac{1}{2} \cdot \mathrm{p} \cdot\left[\begin{array}{l}
\mathbf{i}_{\mathbf{s}} \\
\mathbf{i}_{\mathbf{r}}
\end{array}\right]^{\mathrm{T}} \cdot \frac{\mathrm{d}}{\mathrm{d} \vartheta}\left(\left[\begin{array}{ll}
\mathbf{L}_{\mathbf{s s}} & \mathbf{L}_{\mathbf{s r}} \\
\mathbf{L}_{\mathbf{r s}} & \mathbf{L}_{\mathbf{r r}}
\end{array}\right]\right) \cdot\left[\begin{array}{l}
\mathbf{i}_{\mathbf{s}} \\
\mathbf{i}_{\mathbf{r}}
\end{array}\right]
$$

$\mathrm{M}_{\mathrm{em}}$ - elektromagnetni momenat mašine

p - broj pari polova trofazne asinhrone mašine

$\theta$ - električni ugao koji opisuje trenutni položaj rotora $u$ odnosu na stator

Usled dejstva elektromagnetskih sila, na rotor deluje elektromagnetski momenat $\mathbf{M}_{\mathrm{em}}$. Rotor je preko vratila povezan sa radnom mašinom ili pogonskom turbinom. Vratilo prenosi mehanički momenat $\mathrm{M}_{\mathrm{m}}$. U mehaničkom podsistemu postoje gubici usled trenja i ventilacije, kao i akumulacija kinetičke energije u obrtnim delovima mašine. Stoga mehanički momenat $M_{m}$, koji se ima na izlaznom vratilu nije jednak elektromagnetskom momentu $\mathrm{M}_{\mathrm{em}}$ koji deluje na rotor [1]. Pojave u mehaničkom podsistemu se opisuju i Njutnovom diferencijalnom jednačinom kretanja koja opisuje promenu brzine obrtanja mašine i određena je izrazom:

$$
M_{e m}-M_{m}=J \cdot \frac{d \omega_{m}}{d t}+K_{m} \cdot \omega_{m}
$$

$\mathrm{M}_{\mathrm{m}}$ - mehanički momenat mašine

$\mathrm{J}_{\mathrm{m}}$ - ukupni momenat inercije pokretnog dela pogona

$\mathrm{K}_{\mathrm{m}}$ - koeficijent i ventilacije odnosno koeficijent gubitaka $\omega_{\mathrm{m}}-$ trenutna vrednost mehaničke ugaone brzine

\section{ODREĐIVANJE ELEKTRIČNIH PARAMETARA KAVEZNE ASINHRONE MAŠINE}

Kako bi se mogle izvršiti računarske simulacije korišćenjem navedenog matematičkog modela, neophodno je poznavati vrednosti elemenata svih matrica induktivnosti i otpornosti. Otpornosti namotaja se dobijaju eksperimentalno ili vršenjem adekvatnih proračuna. Za izračunavanje elemenata matrice induktivnosti koristi se metoda 
konačnih elemenata koja podrazumeva sprovođenje niza magnetostatičkih simulacija. To se najčešće realizuje pomoću programskog paketa FEMM 4.2 [5]. Prilikom izvođenja magnetostatičkih simulacija, određeni namotaj ili rotorska petlja se pobuđuje jednosmernom strujom. Zbog uvažavanja postojanja žljebova i promene relativnog međusobnog položaja namotaja statora i rotorskih petlji usled kretanja rotora koje za posledicu ima periodične zavisnosti svih elemenata matrice induktivnosti od položaja rotora, potrebno je izvršiti čitave serije simulacija za različite položaje rotorskog kaveza.

Kada se izračunaju fluksni obuhvati, iz njih se primenom metode konačnih elemenata dobijaju vrednosti nepoznatih induktivnosti $u$ vidu odbiraka. $S$ obzirom na složenoperiodičnu zavisnost induktivnosti od položaja rotora, one se mogu predstaviti preko koeficijenata Furijeovog reda. Prvo se dobijene diskretne vrednosti induktivnosti linearnom interpolacijom moraju predstaviti kao kontinualne funkcije, s obzirom na činjenicu da je razvoj u Furijeov red definisan isključivo za kontinualne funkcije.

Izraz za razvoj sopstvene induktivnosti statorskog namotaja faze a u Furijeov red dat je relacijom (7), a primer izračunavanja ove induktivnosti dat za konkretnu mašinu prikazan je na slici 1 . Kada se izračunata sopstvena induktivnost statorskog namotaja faze a fazno pomeri za $2 \pi / 3$, dobiće se sopstvena induktivnost faze $b$, a kada je fazni pomeraj jednak $+2 \pi / 3$, dobija se sopstvena induktivnost statorskog namotaja faze $\mathrm{c}$.

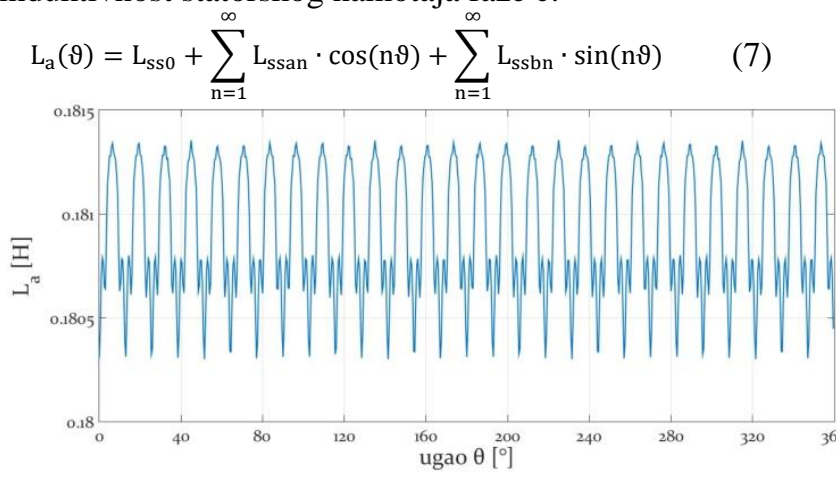

Slika 1. Sopstvena induktivnost statora faze a

Izraz za razvoj međusobne induktivnosti statorskih namotaja $\mathrm{M}_{\mathrm{ab}} \mathrm{u}$ Furijeov red dat je relacijom (8), a primer izračunavanja ove induktivnosti dat za konkretnu mašinu prikazan je na slici 2. Talasni oblici induktivnosti $\mathrm{M}_{\mathrm{ac}} \mathrm{i}$ $M_{b c}$ su isti, ali fazno pomereni za $-2 \pi / 3$, odnosno $+2 \pi / 3$, respektivno.

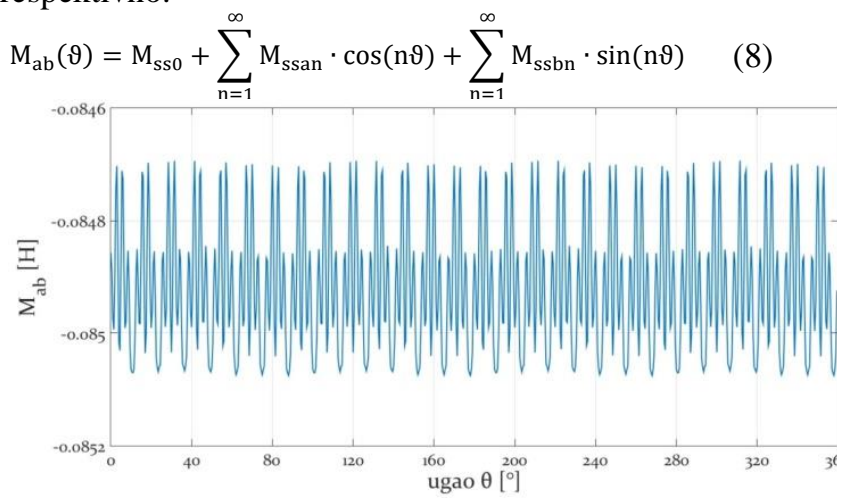

Slika 2. Međusobna induktivnost statorskih namotaja $M_{a b}$
Slika 3 prikazuje talasne oblike međusobnih induktivnosti statorskih namotaja faza a, b i c i prve u nizu rotorskih petlji unutar kratkospojenog kaveznog rotora razmatrane mašine (rotorska petlja sa indeksom 1), a izraz za razvoj induktivnosti $M_{a r 1}$ u Furijeov red je dat relacijom (9). $S$ obzirom na činjenicu da su elementi vrsta submatrice statorsko-rotorskih induktivnosti $\mathbf{L}_{\mathbf{s r}}$ međusobno fazno pomereni za $2 \pi / 3$, talasni oblici predstavljenih induktivnosti su takođe pomereni za isti ugao.

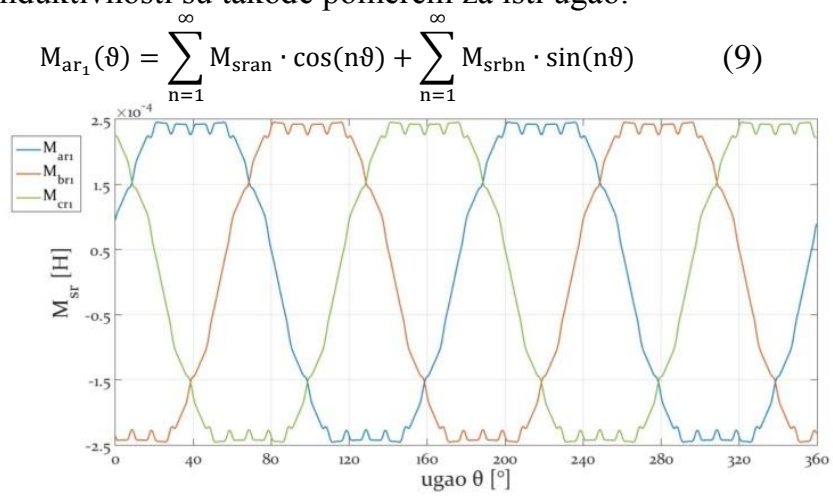

Slika 3. Statorsko-rotorske induktivnosti

Izraz koji predstavlja razvoj u Furijeov red sopstvene induktivnosti prve u nizu rotorskih petlji unutar kaveznog rotora mašine dat je relacijom (10), dok je primer izračunavanja ove induktivnosti prikazan na slici 4 .

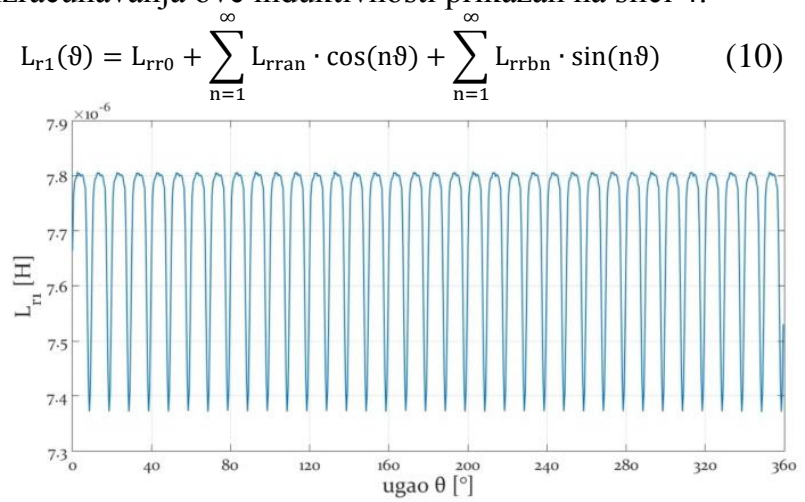

Slika 4. Sopstvena induktivnost prve rotorske petlje

Sve preostale sopstvene induktivnosti rotorskih petlji imaju identičan talasni oblik, uzimajući u obzir odgovarajući fazni pomak između susednih rotorskih petlji za ugao $2 \pi / \mathrm{N}_{\mathrm{B}}$. Na slici 5 prikazana je zavisnost međusobne induktivnosti rotorskih petlji sa indeksima 1 i 2 . Identičan talasni oblik imaju i sve ostale međusobne rotorskorotorske induktivnosti koje se odnose na dve susedne rotorske petlje. Izraz za razvoj pomenute induktivnosti $\mathrm{u}$ Furijeov red, dat je sledećom relacijom:

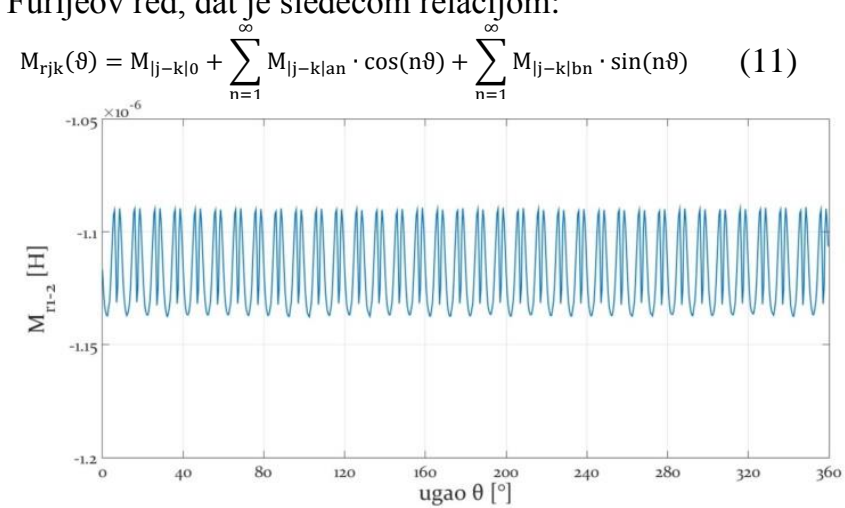

Slika 5. Međusobna induktivnost rotorskih petlji 1 i 2 


\section{MATLAB SIMULACIJE NA RAZVIJENOM MODELU MAŠINE}

Dinamički matematički model trofazne kavezne asinhrone mašine realizovan je u programskom paketu MATLAB Simulink koji omogućava da se putem najrazličitijih računarskih simulacija istraže sve relevantne pojave $i$ fenomeni koji se odvijaju unutar mašine kao sredstva elektromehaničke konverzije energije. Simulacije služe za pribavljanje podataka i informacija o različitim pojavama koje se odvijaju unutar električne mašine bez stvarnih događanja, odnosno, na primeru logičke zamene realnog sistema $\mathrm{u}$ formi matematičkog modela.

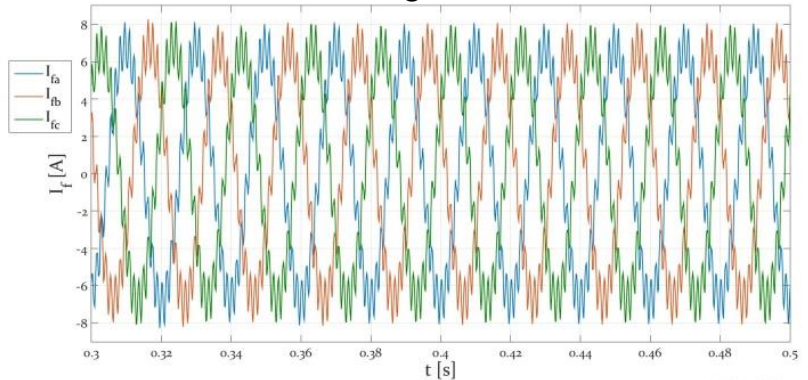

Slika 6. Fazne struje motora u ustaljenom stanju

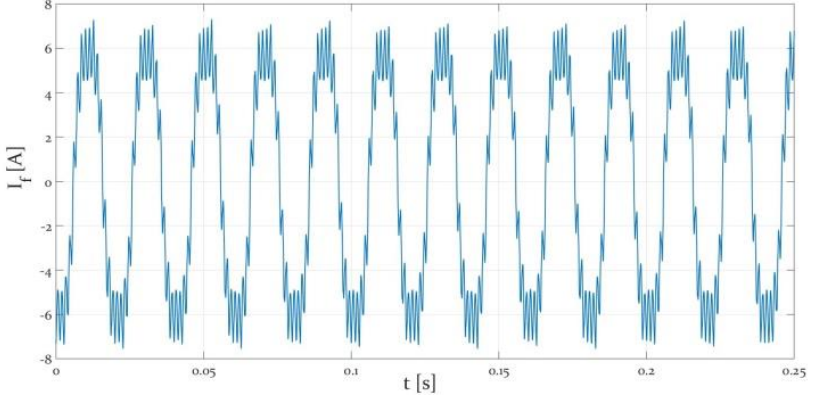

Slika 7. Eksperimentalni odziv fazne struje motora

Na slici 6 prikazan je talasni oblik fazne struje motora $u$ režimu praznog hoda tokom ustaljenog, normalnog pogonskog stanja mašine. Ono što je karakteristično za složenoperiodične talasne oblike prikazanih struja jeste $\mathrm{i}$ primetno prisustvo viših harmonika. Oni su posledica uvažavanja konstrukcionih osobenosti mašine koji su na detaljan način uvaženi u matrici induktivnosti. Na slici 7 prikazan je eksperimantalno dobijen talasni oblik fazne struje tokom istovetnog radnog režima.

$\mathrm{Na}$ slici 8 prikazan je talasni oblik fazne struje motora $\mathrm{u}$ režimu praznog hoda u ustaljenom stanju u slučaju kvara kaveznog rotora. U složenoperiodičnom obliku struja se jasno uočavaju posledice električne neuravnoteženosti mašine nastale usled kvara. Slika 9 prikazuje eksperimantalno dobijen talasni oblik fazne struje tokom istovetnog radnog režima.

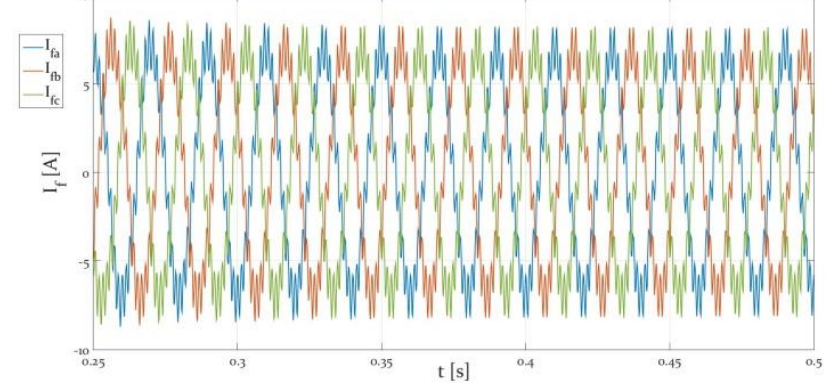

Slika 8. Fazne struje motora u slučaju kvara rotora

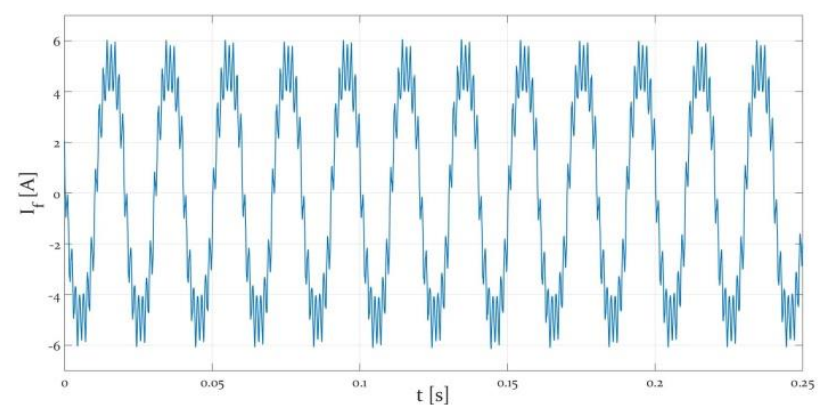

Slika 9. Eksperimentalni odziv fazne struje motora $u$ slučaju kvara rotora

\section{ZAKLJUČAK}

U ovom radu je razvijen dinamički matematički model trofazne kavezne asinhrone mašine čiji se ulazni parametri dobijaju primenom metode konačnih elemenata. Model uvažava uticaj postojanja žljebova na statoru i rotoru mašine. Razvijeni model je na više primera upoređen sa eksperimentalno dobijenim odzivima, pri čemu su uočena veoma zadovoljavajuća poklapanja rezultata.

Model omogućava simulacije različitih scenarija koji se mogu javiti tokom eksploatacije mašine, uključujući i pojavu različitih vrsta kvarova.

\section{LITERATURA}

[1] Slobodan N. Vukosavić, „Električne mašine“, Univerzitet u Beogradu, Elektrotehnički fakultet, „Akademska misao“, 2010.

[2] Dejan Reljić, ,Otkrivanje kvara rotora kaveznog asinhronog motora primenom tehnika analize terminalnih veličina“", doktorska disertacija, Fakultet tehničkih nauka, Novi Sad, 2017.

[3] Vladan Vučković, ,Opšta teorija električnih mašina“, IP ,Nauka“, 2009.

[4] Dejan Jerkan, „Dinamički model trofazne kavezne asinhrone mašine zasnovan na metodi konačnih elemenata", doktorska disertacija, Fakultet tehničkih nauka, Novi Sad, 2016.

[5] http://www.femm.info/wiki/HomePage

\section{Kratka biografija:}

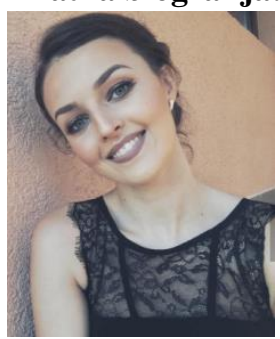

Ivana Ćirić rođena je u Novom Sadu 1994. god. Diplomirala je na Fakultetu tehničkih nauka u Novom Sadu 2018. godine. Master studije iz oblasti Elektrotehnike i računarstva Energetska elektronika i električne mašine je upisala školske 2018./19. godine.

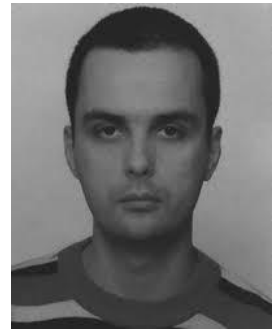

Dejan Jerkan je docent na Fakultetu tehničkih nauka u Novom Sadu, na Katedri za Energetsku elektroniku i pretvarače. Oblast interesovanja su mu modelovanje i dijagnostika električnih mašina, kao i metoda konačnih elemenata. 